\title{
Smart Cooling Controlled System Exploiting Photovoltaic Renewable Energy Systems
}

\author{
Ahmad Atieh"1*, Jamil Al Asfar ${ }^{1}$, Nabeel Tawalbeh¹, Eyas Shaqour¹, \\ Ibrahim Alsalhi' ${ }^{1}$, Othman Istaiteh ${ }^{1}$ \\ 1 School of Engineering, The University of Jordan, Amman, Jordan \\ * Corresponding author's e-mail: akatieh@hotmail.com
}

\begin{abstract}
A smart cooling system to control the ambient temperature of a premise in Amman, Jordan, is investigated and implemented. The premise holds 650 people and has 14 air conditioners with the cooling capacity ranging from 3 to 5 ton refrigerant (TR) each. The control of the cooling system includes implementing different electronics circuits that are used to sense the ambient temperature and humidity, count the number of people in the premise and then turn ON/OFF certain air conditioner(s). The data collected by different electronic circuits are fed wirelessly to a microcontroller, which decides which air conditioner will be turned ON/OFF, its location and its desired set cooling temperature. The cooling system is integrated with an on-grid solar photovoltaic energy system to minimize the operational cost of the overall cooling system.
\end{abstract}

Keywords: smart cooling system, solar system, energy management, cost analysis

\section{INTRODUCTION}

In order to achieve the sufficient comfort levels for occupants to make their stay enjoyable, it is desirable to control the environmental conditions of large area premises. The environmental parameters that affect the comfort levels of the occupants include thermal temperature, humidity, air quality and lighting system. Many research works have been conducted to manage the environmental conditions using different schemes [Thomas et al. 2012, Wang et al. 2012, Mathews et al. 2001, Dounis and Caraiscos 2009]. Some approaches were investigated to control the operation of air conditioners (ACs). The controller part of the management scheme of these ACs uses different control algorithms based on Fuzzy-logic [Calvino et al. 2004, Ari et al. 2005, Nassif et al. 2004] or neural network [Liang and Du 2005]. Typically, there are large number of ACs present in premises, which makes adjusting the temperature of these premises using air conditioners (ACs) without smart control a costly solution, because ACs consume huge amounts of energy. In addition, turning $\mathrm{ON}$ all ACs manually while a low number of occupants is present at the premise and setting the AC cooling temperature at values much lower than the optimal temperature for the premise will cause a waste of energy and an increase in the premise operational cost. Thus, it is desirable to minimize the energy consumption of the premise in order to reduce cost as well as pollution. One solution is to use smart renewable energy sources to power up the different energy-consuming appliances and equipment in premises. Then, smart energy management schemes should be adopted for operating the equipment. Different renewable energy sources are available in the world, depending on the location and climate conditions, which could be used to supply energy to the different loads. Photovoltaic (PV) solar subsystem is one of commonly used renewable energy sources in the Middle East region due to abundance of solar radiation [http://www.nrel.gov/midc/srrl_bms/].

In this work, a simple and smart algorithm is used to manage the comfort level of a premise that is used to host about 650 people. The premise area is equipped with fourteen air conditioners 
with different cooling capacity, used to control its ambient temperature and air quality. The cooling capacities of these air conditioners are different and vary between 3, 4 and 5 TR. One ton refrigerant (TR) is equivalent to $12,000 \mathrm{Btu} / \mathrm{hr}$ (British thermal unit per hour), or about $3.51 \mathrm{~kW}$. The electrical power consumption is around one fourth of the cooling capacity according to the coefficient of performance of the units used. An on-grid solar photovoltaic energy is used to power these air conditionerss in order to control the operational cost of the premise. The PV solar subsystem is composed of 50 panels, $300 \mathrm{~W}$ each, which produces $15 \mathrm{~kW}$ peak power.

\section{METHODOLOGY}

A smart cooling system to control the ambient temperature of a premise located in Amman, Jordan, is investigated and implemented. The smart cooling system includes two management sections. The first part includes the electronic circuitries that manage the operation of the different air conditioners in the premise, sense the ambient temperature and count the number of people in the premise. The second part includes the solar photovoltaic (PV) renewable energy subsystem that is used to power the air conditions. A smart control system adopted for this premise uses a feedback mechanism to control the number of ACs that will be turned ON, their location, and the AC set cooling temperature. The layout of the air conditioners and their cooling capacities is shown in Figure 1. The control system is managed through electronic circuits that identify the number of people that enters the premise and their seating. The circuit uses the number of people and the ambient temperature of the premise to send wirelessly a control signal to turn $\mathrm{ON}$ a specific AC. The load energy used in the modeling includes the energy generated by the people inside the premise and the set temperature that needs to be achieved. The energy produced by individuals is calculated based on the energy they produce while seating or doing an activity, the features of the premise in terms of its dimensions, the number of windows and their locations, and the airflow. The seating in the premise is planned as 65 people per line and when the first line is filled, then it continues on to the next line and so on. A lookup table is used to decide which air conditioner is turned $\mathrm{ON}$ based on its cooling capacity, location, number of people and their seating in the premise.

The cooling load of the selected area is calculated based on $42^{\circ} \mathrm{C}$ outside temperature $\left(110^{\circ} \mathrm{F}\right)$ and $22^{\circ} \mathrm{C}\left(70^{\circ} \mathrm{F}\right)$ inside temperature. The desired relative humidity of the inside space was taken as $30 \%$ according to comfort requirements. The calculations of the cooling demand were performed using two methods: manual calculations and block load software. The cooling load consists of two parts: fixed one and variable one. The fixed load is due to building characteristics such as insulation, sun-oriented radiation, overall heat transfer coefficient of the roof, walls, glass windows, floor, doors, lighting and electrical equipment. The variable load is due to the number of occupants in the selected area, their activity type and length of stay. The calculated cooling load also includes the infiltration required by the occupants, in addition to sensible and latent heat resulting from their presence. The fixed cooling load reached 9 TR (around $106000 \mathrm{Btu} / \mathrm{hr}$ ), while the variable cooling load may reach $592000 \mathrm{Btu} /$ $\mathrm{hr}$ if the number of occupants reaches 650 people [Fasfous et al. 2013].

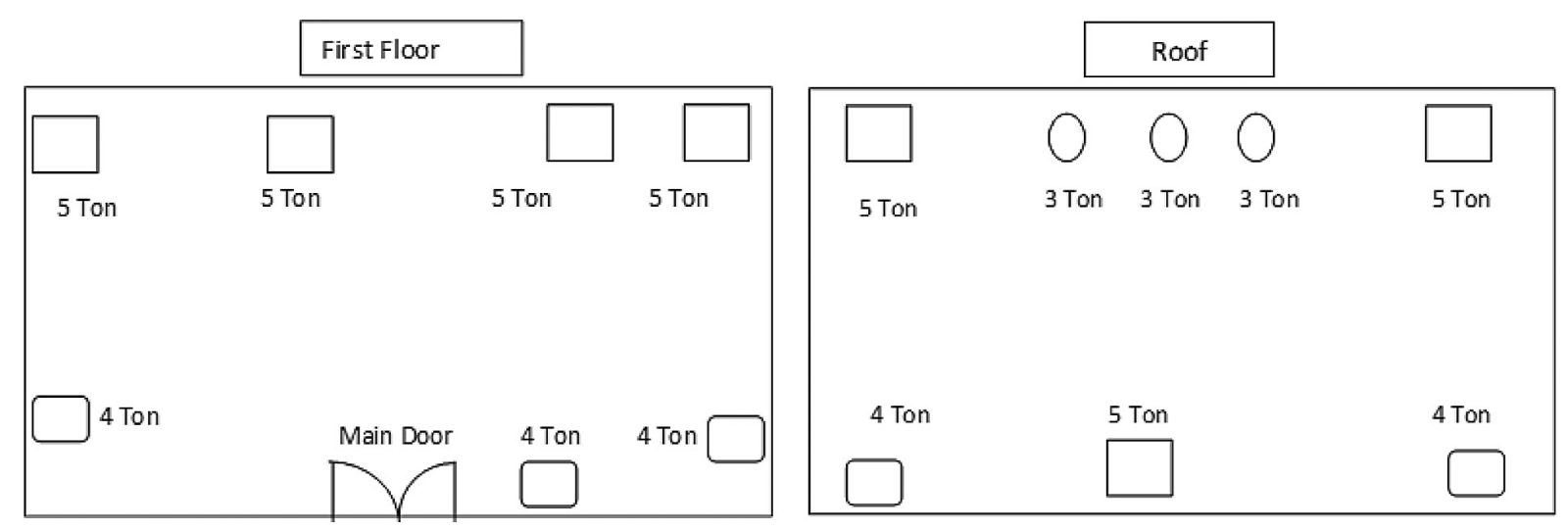

Figure 1. Layout of air-conditioners in the premise and their cooling capacities 
A microcontroller based circuit is designed to count the number of people enters and stays in the premise based on an infrared sensors technology. The ambient temperature and humidity of the premise are monitored using sensors that are located at different places. The sensor data and the desired cooled temperature of the premise are fed to the microcontroller. A lock-up table, stored in the microcontroller, is used to control the sequence of air conditioners that are turned ON/OFF to achieve the desired temperature in the premise. The lock-up table is shown (Table 2).

\section{CONTROL UNIT}

Different measured parameters of the smart cooling system are used as inputs to the control unit. These parameters include the power produced by the PV subsystem, power consumption of relevant operational air conditioners, heat transfer characteristics of the premise, number of people present in the premise, ambient temperature and desired cooling temperature. The power consumption of an air conditioner is a function of the cooling set temperature, which is related to the amount of time an $\mathrm{AC}$ will take to reach a set cooling temperature. The $\mathrm{AC}$ will take longer time if the desired set values are far from the ambient temperature. The calculated total fixed heat gain of the premises is 35000 $\mathrm{Btu} / \mathrm{hr}$, while the heat radiated by each person entering the premise is assumed to be 1,184 $\mathrm{Btu} / \mathrm{hr}$. Thus, for a single row that would handle 65 people, the total heat gain will reach 11,960 $\mathrm{Btu} / \mathrm{hr}$ including infiltration. Therefore, we assumed that every ten people would require $1 \mathrm{TR}$ AC capacity [Wang et al. 2012]. It is also assumed that an $\mathrm{AC}$ requires about $15 \mathrm{~min}$ to stabilize its temperature to the set cooling value.

An Arduino UNO microcontroller (ATmega328P) is used in the control circuit. Humidity and temperature sensors are used to monitor the premise ambient temperature. A $433 \mathrm{MHz}$ RF wireless transmitter and receiver are used to establish communication between the sensors, microcontroller and the air condition control circuitry in order to turn a specific $\mathrm{AC} \mathrm{ON} / \mathrm{OFF}$ and to set its cooling temperature. Two infrared (IR) lasers and corresponding detectors are used in a circuit to count the number of people entering and leaving the premise. The two lasers and detectors are placed in parallel at the entrance of the premise in such a way that if the first laser beam has been cut first, then a person is entering the premise and if the second laser beam is cut first, then a person is leaving the premise. The electronic circuits that are used to count the people in and out of the premise, to measure the temperature and humidity, to display outputs on microcontroller, and to control the operation of different ACs are shown in Figure 2. The signals of the sensors and IR counters are transmitted wirelessly to the microcontroller which is equipped with a lock-up table that is used to decide when an air condition is turned ON/OFF, its location, and its desired cooling temperature.

\section{ECONOMIC ANALYSIS}

The electric power consumption of an air conditioner is not directly related to the $\mathrm{AC}$ set cooling temperature. This meansthat setting the AC temperature to $25{ }^{\circ} \mathrm{C}$ or $28{ }^{\circ} \mathrm{C}$ is not directly related to the electric power consumption. However, it is related to the time it will take the $\mathrm{AC}$ to reach the set value from the ambient temperature, which requires the $\mathrm{AC}$ compressor to work harder. The AC will need to work longer to reach $25{ }^{\circ} \mathrm{C}$ compared to 28 ${ }^{\circ} \mathrm{C}$. Once the desired temperature is reached, the compressor stops working and only the AC fans works. According to the American Society of Heating, Refrigerating and Air Conditioning Engineers (ASHRAE), the comfort temperature in the summer is about $22{ }^{\circ} \mathrm{C}$.

The running cost of a cooling system includes the cost of air conditioners which is typically related to their cooling capacity, the time of operating the air conditioners which is related to their set cooling temperature value, the ambient temperature, and the price of electricity provided by the utility company.

The solar PV subsystem is composed of 50 panels that are connected to a 3 -phase $15 \mathrm{~kW}$ inverter. The PV panels are polycrystalline with peak power of $300 \mathrm{~W}$. The hourly average solar radiation for the city of Amman for the month of July over 10 years is shown in Figue 3. The premise is connected to the grid through a twoway meter. Figure 4 illustrates the monthly produced solar power in the period between Jan $1^{\text {st }}$ to Dec $25^{\text {th }}$ of 2015 . On the other hand, Figure 5 
a)

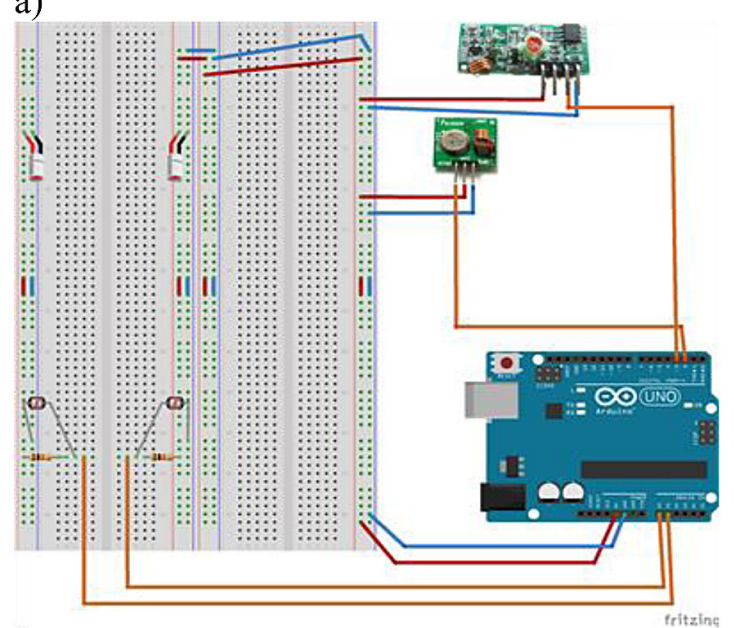

c)

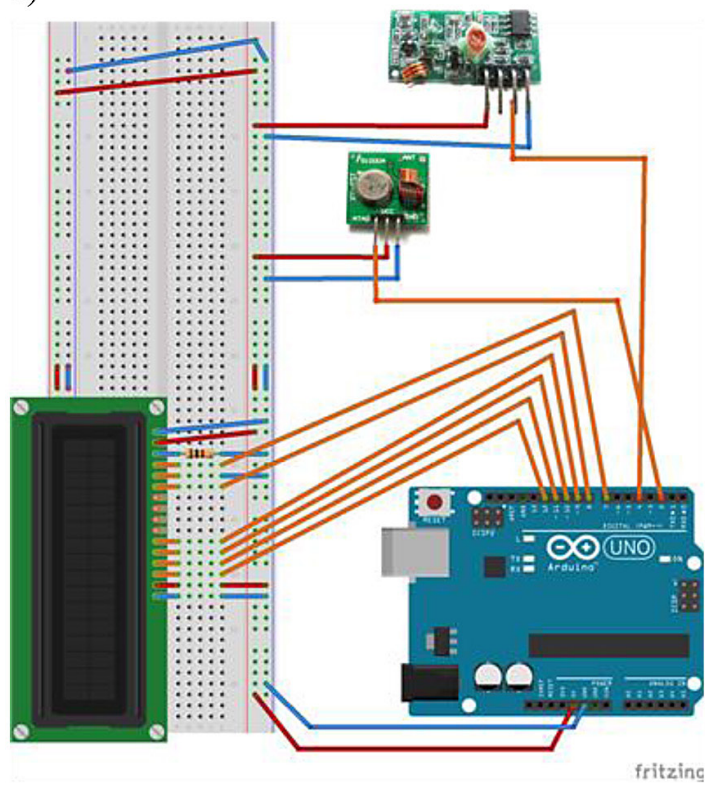

b)

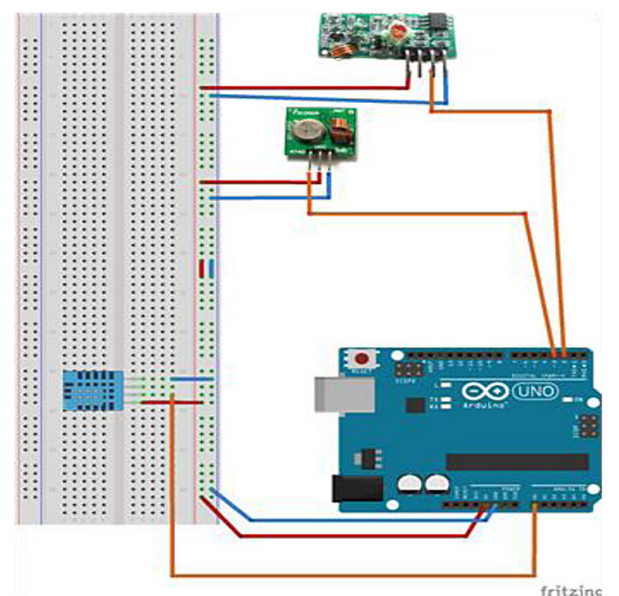

d)

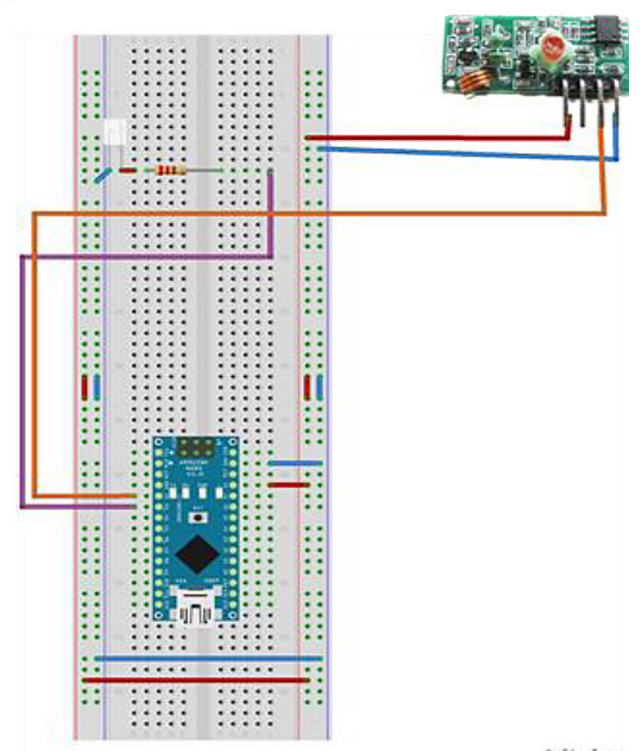

Figure 2. Circuit diagrams of the different electronic parts used for controlling the temperature of the premise. (a) People counting circuit. (b) Temperature/Humidity sensor circuit. (c) Main controller circuit. (d) AC control unit

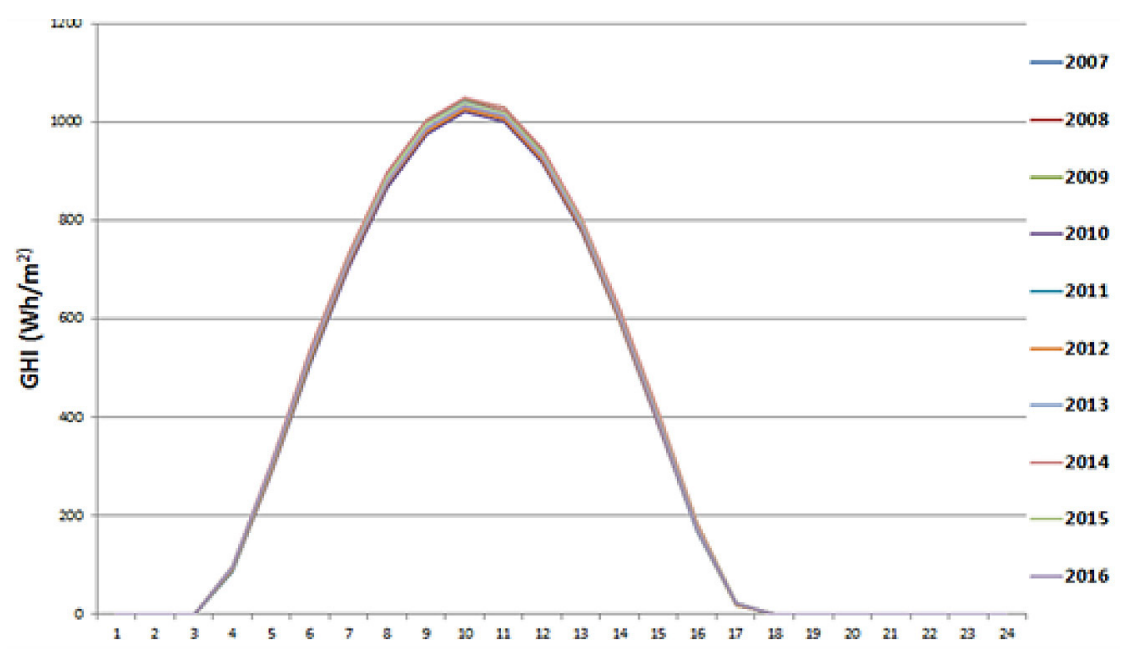

Figure 3. The hourly average solar radiation for the month of July over 10 years in Amman 


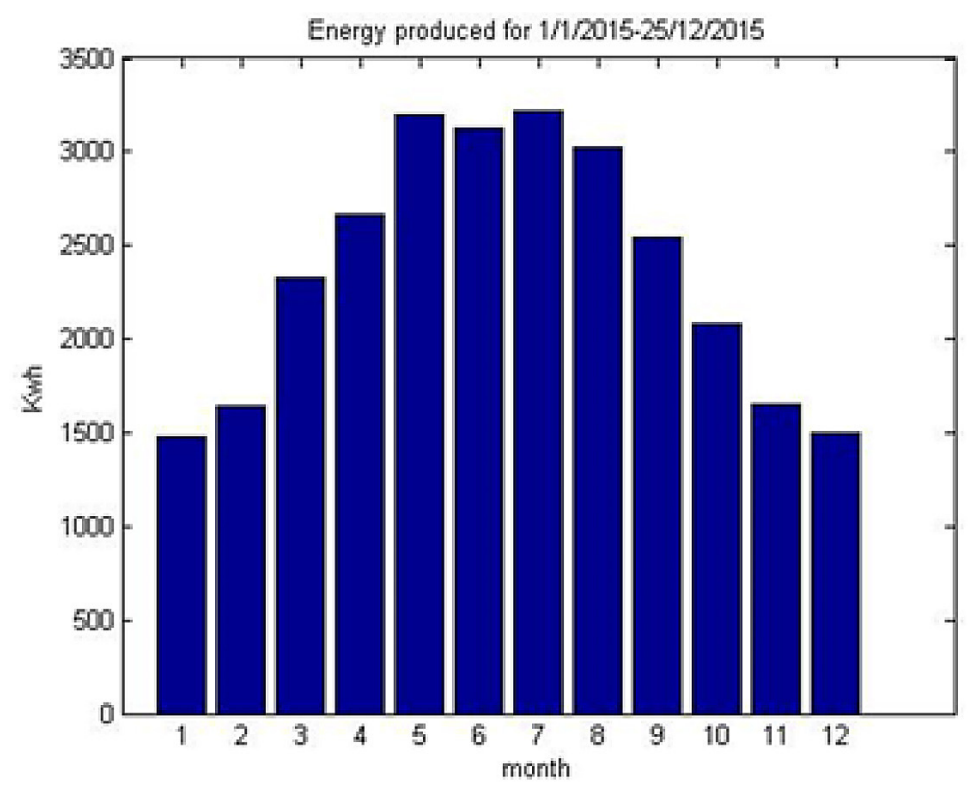

Figure 4. Monthly power produced by the solar renewable subsystem for one year

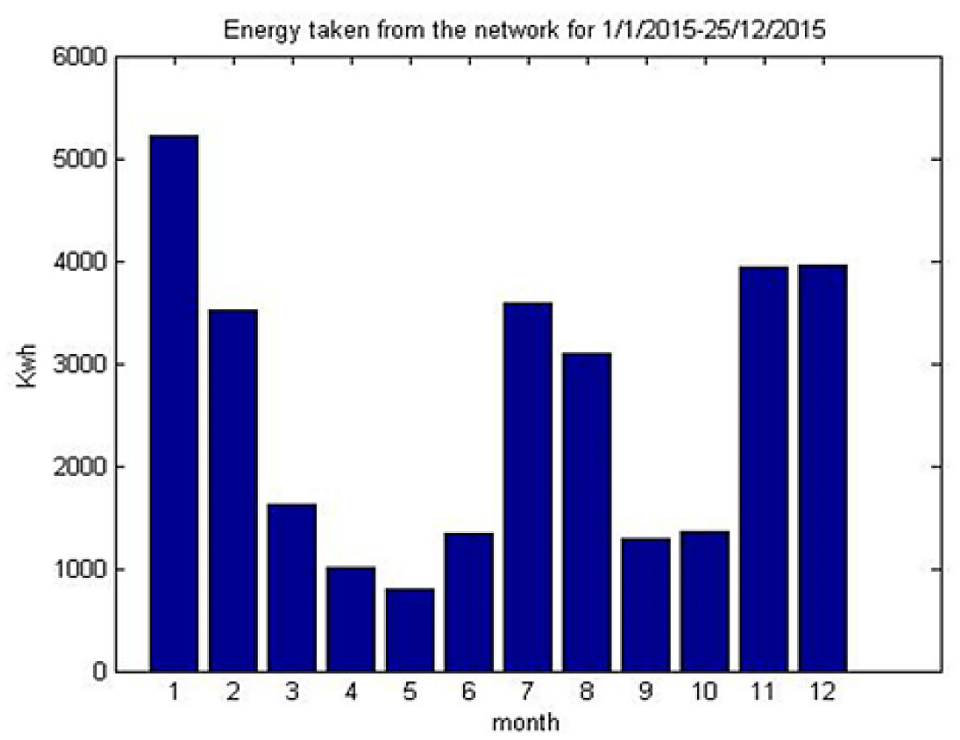

Figure 5. The energy consumed by the premise and supplied by the grid for one year

shows the premise power consumption from the grid for the same period. Table 1 shows the cost of electricity offered by the utility company in Jordan. The net power consumed by the premise after deducting the power consumed by the grid and produced by the PV subsystem is shown in Figure 6. When the net power is negative, the premise consumed more power from the grid than what was produced by the solar renewable energy subsystem, hence the premise will be charged based on the energy cost listed in Table 1. The excess produced power is credited for the premise based on a price of $0.120 \mathrm{Fils} / \mathrm{kWh}$ $(0.169 \$ / \mathrm{kWh})$.

\section{CONCLUSIONS}

A smart cooling system for controlling the ambient temperature for a premise that has the capacity of 650 people is investigated and implemented. The ambient temperature, humidity and air quality are controlled using 14 air conditioning units of variable cooling capacities located at different places in the premise. The air conditioners are powered-up using solar renewable energy subsystem in order to reduce the cost of operation of the cooling system. The PV solar system produces $15 \mathrm{~kW}$ peak power. The economics of the whole system is also presented. 
Table 1. Price of electricity offered by the utility company

\begin{tabular}{|l|c|c|}
\hline Household energy consumption & Fils/kWh & \$US/kWh \\
\hline First Block: from 1-160 kWh/Month & 33 & 0.0465 \\
\hline Second Block: from 161-300 kWh/Month & 72 & 0.101 \\
\hline Third Block: from 301-500 kWh/Month & 86 & 0.121 \\
\hline Fourth Block: from 501-600 kWh/Month & 114 & 0.161 \\
\hline Fifth Block: from 601-750 kWh/Month & 158 & 0.223 \\
\hline Sixth Block: from 751-1000 kWh/Month & 188 & 0.265 \\
\hline Seventh Block: more than 1000 kWh/Month & 265 & 0.373 \\
\hline
\end{tabular}

Table 2. Look-up table used by the microcontroller to control the operation of ACs

\begin{tabular}{|c|c|c|c|}
\hline Row number & $\begin{array}{l}\text { Number of people in } \\
\text { premise }\end{array}$ & $\begin{array}{l}\text { AC ON/OFF and its cooling } \\
\text { capacity (Ton) }\end{array}$ & Comments \\
\hline 1 & Up to 65 & C: ON and B: ON (10 Ton) & \\
\hline 2 & $\begin{array}{l}\text { Add } 30 \text { people } \\
\text { Add } 30 \text { people }\end{array}$ & $\begin{array}{l}\text { 2: ON (3 Ton) } \\
\text { 3: ON (3 Ton) }\end{array}$ & $\begin{array}{l}\text { When number of people }>125 \text {, turn } A \text { : ON for } 15 \text { min } \\
\text { to stabilize then turn OFF both } 2 \text { and } 3(A, B, C: O N)\end{array}$ \\
\hline 3 & $\begin{array}{l}\text { Add } 30 \text { people } \\
\text { Add } 30 \text { people }\end{array}$ & $\begin{array}{l}\text { A: ON (5 Ton), 2: OFF, 3: OFF } \\
\text { 2: ON (3 Ton) }\end{array}$ & \\
\hline 4 & $\begin{array}{l}\text { Add } 30 \text { people } \\
\text { Add } 30 \text { people }\end{array}$ & $\begin{array}{l}\text { 3: ON (3 Ton) } \\
\text { D: ON (3 Ton), 3: OFF }\end{array}$ & $\begin{array}{l}\text { When number of people }>215 \text {, turn } D: \text { ON for } 15 \text { min } \\
\text { to stabilize then turn } 3 \text { OFF }(A, B, C, D, 2: \text { ON })\end{array}$ \\
\hline 5 & $\begin{array}{l}\text { Add } 30 \text { people } \\
\text { Add } 30 \text { people }\end{array}$ & $\begin{array}{l}\text { 3: ON (3 Ton) } \\
\text { V: ON (4 Ton) }\end{array}$ & $\begin{array}{l}\text { When the number of people }>305 \text { turn } \mathrm{V} \text { : ON for } 15 \\
\text { min to stabilize (A, B, C, D, V, 2, 3: ON) }\end{array}$ \\
\hline 6 & $\begin{array}{l}\text { Add } 30 \text { people } \\
\text { Add } 30 \text { people }\end{array}$ & $\begin{array}{l}\text { U: ON (4 Ton) } \\
\text { 1: ON (3 Ton) }\end{array}$ & $(\mathrm{A}, \mathrm{B}, \mathrm{C}, \mathrm{D}, \mathrm{U}, \mathrm{V}, 1,2,3: \mathrm{ON})$ \\
\hline 7 & $\begin{array}{l}\text { Add } 30 \text { people } \\
\text { Add } 30 \text { people }\end{array}$ & W: ON (4 Ton) & $\begin{array}{l}(\mathrm{A}, \mathrm{B}, \mathrm{C}, \mathrm{D}, \mathrm{U}, \mathrm{V}, \mathrm{W}, 1,2,3: \mathrm{ON})=41 \text { Ton } \\
425 \text { people }\end{array}$ \\
\hline 8 & $\begin{array}{l}\text { Add } 30 \text { people } \\
\text { Add } 30 \text { people }\end{array}$ & $\begin{array}{l}\text { Z: ON (5 Ton) } \\
\text { E: ON (4 Ton) }\end{array}$ & $\begin{array}{l}50 \text { Ton } \\
485 \text { people }\end{array}$ \\
\hline 9 & $\begin{array}{l}\text { Add } 30 \text { people } \\
\text { Add } 30 \text { people }\end{array}$ & F: ON (4 Ton) & $\begin{array}{l}54 \text { Ton } \\
545 \text { people }\end{array}$ \\
\hline 10 & $\begin{array}{l}\text { Add } 30 \text { people } \\
\text { Add } 30 \text { people }\end{array}$ & $\begin{array}{l}\text { X: ON (5 Ton) } \\
\text { Y: ON (5 Ton) }\end{array}$ & $\begin{array}{l}64 \text { Ton } \\
635 \text { people }\end{array}$ \\
\hline
\end{tabular}

\section{REFERENCES}

1. Ari S., Cosden I.A., Khalifa H.E., Dannenhoffer J.F., Wilcoxen P., and Isik C., 2005. Constrained fuzzy logic approximation for indoor comfort and energy optimization. In: Proc. IEEE Fuzzy Inf. Process. Soc. Annu. Meet., Jun., 500-504.

2. Calvino F., La Gennusa M., Rizzo G., and Scaccianoce G., 2004. The control of indoor thermal comfort conditions: Introducing a fuzzy adaptive controller," Energy Buildings, 36(2), 97-102.

3. Dounis A.I. and Caraiscos C., 2009. Advanced control systems engineering for energy and comfort management in a building environment-A review. Renewable Sustainable Energy Rev., 13(6-7), 1246-1261.

4. Fasfous J. Al Asfar, Hamdan M.A., Al-Salaymeh A., Sakhrieh A., Al-hamamre Z., and Al-bawwab A., 2013. Potential of utilizing solar cooling in the University of Jordan. Energy Conversion and Management, vol. 65, 729-735.

5. Liang J. and Du R., 2005. Thermal comfort control based on neural network for HVAC application," in
Proc. IEEE Control Appl. Conf., Toronto, Canada, 819-824.

6. Mathews E.H., Botha C.P., Arndt D.C., and Malan A., 2001. HVAC control strategies to enhance comfort and minimise energy usage. Energy Buildings, 33(8), 853-863.

7. Nassif N., Kajl S., and Sabourin R., 2004. Evolutionary algorithms for multi-objective optimization in HVAC system control strategy. In: Proc. IEEE North Amer. Fuzzy Inf. Proc. Soc. Annu. Meet. (NAFIPS), Banff, Canada, Jun., vol. 1, 51-56.

8. National Solar Radiation Data Base, Typical Meteorological Year 2. Solar Radiation Research Laboratory (online: http://www.nrel.gov/midc/srrl_bms/).

9. Thomas A.G., Jahangiri P., Wu D., Cai C., Zhao H., Aliprantis D.C., Tesfatsion L., 2012. Intelligent Residential Air-Conditioning System With Smart-Grid Functionality. IEEE Transactions on Smart Grid, 3(4), 2240-2251.

10. Wang Z., Wang L., Dounis A.I., Yang R., 2012. Multi-agent control system with information fusion based comfort model for smart buildings. Applied Energy, vol. 99, 247-254. 